\title{
Prevalence and correlates of smoking on the roof of the world
}

\author{
Syed MA Shah, Ahmed A Arif, George L Delclos, Asif R Khan, A Khan
}

Department of Community Health Sciences, the Aga Khan University, Karachi, Pakistan S M A Shah

A R Khan

Department of Epidemiology, University of Texas HSC, School of Public Health, Houston, Texas, USA A A Arif

G L Delclos

Department of Internal Medicine, Division of Renal

Disease and

Hypertension,

University of Texas

Medical School,

Houston

A Khan

Correspondence to: Dr MA Shah, 7900 Cambridge \# $18-1 \mathrm{H}$, Houston TX 77054 USA

shah@sph.uth.tmc.edu

Received 2 May 2000 and in revised form

5 November 2000. Accepted 7 November 2000

\begin{abstract}
Objective-To determine the prevalence and correlates of cigarette smoking among adults in high mountain rural areas of northern Pakistan.

Design-Cross sectional survey.

Participants-A sample of 4203 adults (aged 18 years and over) were selected by stratified random sampling from 16 villages.

Main outcome measure-Self reported smoking prevalence; age of smoking initiation; daily cigarette consumption and association between current smoking and sociodemographic variables, use of snuff, wine, body mass index, blood pressure, family history of stroke, and hypertension.
\end{abstract}

Results-614/1406 men (43.7\%) and $154 / 2797$ (5.5\%) women reported smoking cigarettes. The age standardised prevalence of smoking was $40.5 \%$ for men and $6.3 \%$ for women. Men were more likely (odds ratio (OR) $6.5,95 \%$ confidence interval (CI) 4.75 to 8.79 ) to be smokers. Smokers were more likely to use snuff (OR $1.39,95 \%$ CI 1.12 to 1.73 ), drink wine (OR $3.47,95 \%$ CI 2.81 to 4.29 ), and were more likely to work as farmers (OR $1.55,95 \%$ CI 1.05 to 2.29 ) or shopkeepers (OR $2.63,95 \%$ CI 1.67 to 4.14$)$. Individuals with college level education and with desirable body mass index were less likely to smoke (OR $0.55,95 \%$ CI 0.35 to 0.87 ; OR $0.74,95 \%$ CI 0.57 to 0.96 ).

Conclusion-Cigarette smoking is a major public health problem in this high mountain community of Pakistan, particularly among the male population, the majority of whom begin to smoke quite early in life. A comprehensive tobacco control effort incorporated into the existing community based health infrastructure is needed.

(Tobacco Control 2001;10:e1)

Keywords: Pakistan; prevalence of smoking

Cigarette smoking was introduced in Pakistan by an English ambassador through the court of Akbar the Great as early as 300 years ago. The king developed a liking for tobacco, which soon spread to his subjects. ${ }^{1}$ About 47 brands of cigarette are consumed in the country, containing some of the highest concentrations of tar and nicotine in the world. ${ }^{2}$ The multinational tobacco companies are doing their best to increase cigarette consumption, reflected in the rapid expansion of the industry ( $5 \%$ per year). ${ }^{3}$ Tobacco is also used in other forms such as hookah (hubble bubble), moist snuff used as an oral dip (niswar), chewed with betel nut (pan), and smoking of rolled dry leaves containing tobacco (beedi). ${ }^{4}$ Cardiovascular diseases, lung cancer, chronic bronchitis, and respiratory diseases resulting from rising tobacco consumption already pose enormous problems on the exiting health infrastructure in Pakistan. Cardiovascular disease is the leading cause of death among males and females aged 15-59 years in the low socioeconomic urban strata of the population. ${ }^{5}$ It is estimated that increasing numbers of relatively young patients with coronary heart disease will visit hospitals that lack resources to address the high cost of diagnosis and therapeutic management. Rising cigarette consumption in Pakistan warrants an early and effective public health response. We conducted a study in northern areas of Pakistan to assess tobacco use. The government health department is the major health provider in the area, mostly via clinics. The Aga Khan Health Services Pakistan (AKHSP), a non-profit non-governmental organisation, has established a number of community based primary health care programmes to address maternal and child health issues in the region and is the second largest health provider. The infant mortality rate has been reduced to 40 per 1000 live births, which is almost half of the national average (74/1000 live births). ${ }^{6}$ With improvement in maternal and child health, diseases of post transition such as cardiovascular and other noncommunicable diseases are emerging as community priority issues.

\section{Methods}

In 1995 we surveyed a random sample of adults aged 18 years and over living in high mountain rural villages of north Pakistan to estimate current prevalence and correlates of cigarette use. This area is situated at the confluence of three mighty mountain rangesthe Himalayas, the Karakoram, and the Hindukush.

The target study population was all adults age 18 years and older residing in villages of the Ghizar district (total population 120 000). We then randomly selected the Punial valley of the 
Table 1 Age and sex distribution of study subjects, Ghizar, Pakistan, 1995

\begin{tabular}{lcc}
\hline Age (years) & Male $n(\%)$ & Female $n(\%)$ \\
\hline $18-29$ & $360(25.60)$ & $1101(39.36)$ \\
$30-39$ & $256(18.21)$ & $605(21.63)$ \\
$40-49$ & $236(16.79)$ & $447(15.98)$ \\
$50-59$ & $260(18.49)$ & $376(13.44)$ \\
$60+$ & $294(20.91)$ & $268(9.58)$ \\
Total & 1406 & 2797 \\
\hline
\end{tabular}

Ghizar district, consisting of 16 villages. The AKHSP maintained a complete listing of residents, total households, and total number of people for each village in the target population. This list was used as the sampling frame for this study. We had to examine 800 households to get a calculated sample of 4000 people aged 18 years and over. We randomly sought households from each of the 16 villages, with the number of households chosen per village proportional to the population within that village.

To select the required number of households from each village, a map of the village with important landmarks was prepared. Shops, schools, and mosques served as village landmarks. A landmark in each of the village was randomly selected serving as a starting point. In each of the starting points a soda bottle was rotated and a household in the direction of the open end of the bottle was visited. The next house was that which was nearest to the first household and this process was repeated until the required number of houses for that village was enrolled. Trained national health workers interviewed respondents at home and obtained data on smoking, snuff (smokeless tobacco), age, sex, education, occupation, income, and wine consumption by administering a pilot tested structured questionnaire. Interviewers used a calendar of local events to obtain the correct age of study subjects. Respondents who were currently smoking and who had smoked $\geqslant 100$ cigarettes in their lifetime were defined as cigarette smokers. Respondents answering yes to the question "Do you ever use snuff/wine" were classified as

Table 2 Sex and age specific prevalence of smoking

\begin{tabular}{lrrlrrl}
\hline $\begin{array}{l}\text { Age } \\
\text { (years) }\end{array}$ & $n$ & \multicolumn{1}{l}{$\begin{array}{l}\text { Male } \\
\text { smokers (\%) }\end{array}$} & 95\% CI & $n$ & $\begin{array}{l}\text { Female } \\
\text { smokers (\%) }\end{array}$ & 95\% CI \\
\hline All & 1406 & $614(43.7)$ & 41.06 to 46.31 & 2797 & $153(5.5)$ & 04.66 to 06.38 \\
$18-29$ & 360 & $70(11.4)$ & 09.73 to 13.06 & 1101 & $13(8.5)$ & 07.46 to 09.53 \\
$30-39$ & 256 & $107(17.4)$ & 15.42 to 19.38 & 605 & $25(16.3)$ & 14.93 to 17.67 \\
$40-49$ & 236 & $120(19.5)$ & 17.43 to 21.57 & 447 & $45(29.4)$ & 27.71 to 31.08 \\
$50-59$ & 260 & $161(26.2)$ & 23.90 to 28.49 & 376 & $42(27.5)$ & 25.85 to 29.15 \\
$60+$ & 294 & $156(25.4)$ & 23.12 to 27.67 & 268 & $28(18.3)$ & 16.87 to 19.73 \\
\hline
\end{tabular}

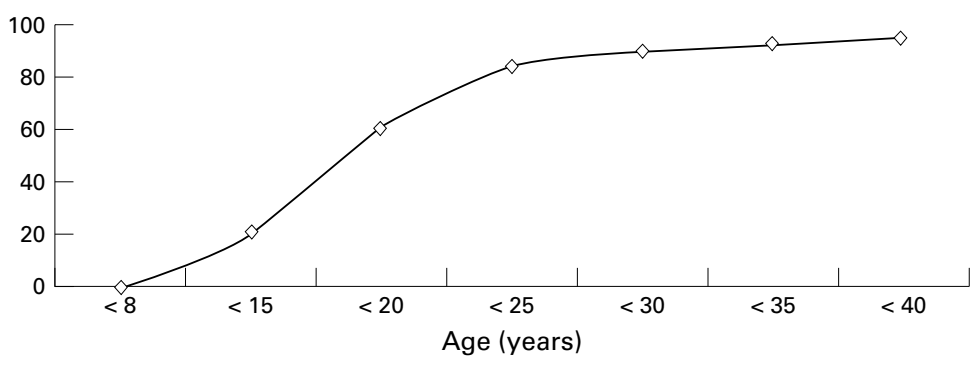

Figure 1 Cumulative percentages of recalled age at which respondent began smoking $(n=4203)$. snuff users and wine users. Occupation was classified into four groups: group 1 -housewives, students, unemployed people; group 2-farmers and unskilled workers; group 3-businessmen, and skilled workers; group 4-government employees. Body mass index was calculated as weight $(\mathrm{kg}) /$ height $(\mathrm{m})^{2}$.

\section{DATA ANALYSIS}

Where possible the questionnaire data were pre-coded for ease and accuracy of collection and checked for any errors of translation. Questionnaire responses were entered into a FoxPro $^{7}$ database using a double entry method. Odds ratios and $\chi^{2}$ test of significance were used to assess the association between possible risk factors and cigarette smoking. Univariate and multivariate logistic regression analyses were carried out using STATA. ${ }^{8}$ Use of cigarette was used as a dependent variable and use of snuff, wine, body mass index, and family history of hypertension were taken as predictor variables in the final model. Data were adjusted for age and sex and are presented separately for men and women in the univariate analysis and combined in the multivariate model. Effect modification between the covariates was also analysed.

\section{Results}

A total of 4203 persons aged 18 years and over in $790 / 800$ households agreed to participate. There were 2797 females (mean age 36 years) and 1406 males (mean age 42 years) in our sample (table 1). Many males were away from home either serving in the army or living down country to earn a livelihood. Proxy responses were not accepted.

The overall reported prevalence of cigarette smoking was $43.7 \%$ among males and 5.5\% among females (table 2). The age adjusted prevalence was $40.5 \%$ among males and $6.3 \%$ among females. The prevalence of smoking increased with age in both men and women and was the highest in the 50-59 age group. Men reported an average daily consumption of 14 cigarettes (95\% confidence interval (CI) 12 to 15), while women reported 12 cigarettes (95\% CI 8 to 16). Among men 317 (12.5\%) reported use of both cigarette and snuff while a very small number of women used tobacco $(42$ or $1.5 \%)$. Study respondents recalled the age they commenced smoking as early as eight years, with $80 \%$ commencing by the age of 25 years (fig 1).

Among the study subjects (table 3), men with college level education were less likely to smoke cigarettes (odds ratio (OR) 0.37, 95\% CI 0.26 to 0.52 ). Among both men and women prevalence of smoking was associated with occupation, use of snuff, drinking wine, and desirable body mass index.

In the multiple logistic regression analysis (table 4) education was an important correlate of smoking. Study subjects with college level education were 0.55 times as likely to be smokers when compared with those with no education. We did not find a significant association of primary level education with cigarette use. 
Table 3 Correlates of cigarette smoking in univariate analysis in Ghizar, Pakistan, 1995

\begin{tabular}{|c|c|c|c|c|}
\hline Characteristics & Men smoking $n(\%)$ & Odds ratio $(95 \% \mathrm{CI})$ & Women smoking $n(\%)$ & Odds ratio $(95 \% \mathrm{CI})$ \\
\hline Sex & $614(43.7)$ & $13.40(11.03$ to 16.27$)$ & $153(5.5)$ & 1.0 \\
\hline \multicolumn{5}{|l|}{ Education } \\
\hline None & $357(49.4)$ & 1.00 & $135(6.7)$ & 1.0 \\
\hline Primary & $205(42.1)$ & $0.75(0.59$ to 0.94$)$ & $15(2.3)$ & $0.33(0.19$ to 0.56$)$ \\
\hline College & $52(26.5)$ & $0.37(0.26$ to 0.52$)$ & $3(2.6)$ & $0.37(0.12$ to 1.17$)$ \\
\hline \multicolumn{5}{|l|}{ Occupation } \\
\hline Group 1 & $81(39.5)$ & $2.44(1.61$ to 3.72$)$ & $133(5.4)$ & $5.30(1.30$ to 20.58$)$ \\
\hline Group 2 & $388(50.9)$ & $3.88(2.75$ to 4.47$)$ & $14(15.9)$ & 17.50 (3.88 to 78.90$)$ \\
\hline Group 3 & $95(47.0)$ & $3.32(2.19$ to 5.04$)$ & $4(6.0)$ & $5.87(1.05$ to 32.84$)$ \\
\hline Group 4 & $50(21.1)$ & 1.00 & $2(1.1)$ & 1.00 \\
\hline \multicolumn{5}{|l|}{ Income } \\
\hline$<3000$ & $354(42.3)$ & 1.00 & $81(5.1)$ & 1.00 \\
\hline $3000-5000$ & $124(45.6)$ & $1.14(0.87$ to 1.51$)$ & $39(7.2)$ & 1.45 (0.98 to 2.15$)$ \\
\hline$>5000$ & $136(45.8)$ & $1.15(0.88$ to 1.50$)$ & $33(5.1)$ & $0.99(0.66$ to 1.51$)$ \\
\hline \multicolumn{5}{|l|}{ Use of snuff } \\
\hline Yes & $317(57.3)$ & $2.51(2.02$ to 3.13$)$ & $42(10.9)$ & $2.53(1.74$ to 3.67$)$ \\
\hline No & $297(34.8)$ & 1.00 & $111(4.6)$ & 1.00 \\
\hline \multicolumn{5}{|l|}{ Drink wine } \\
\hline No & $131(23.4)$ & 1.00 & $84(3.5)$ & 1.00 \\
\hline Yes & $483(57.2)$ & 4.38 (3.45 to 5.56$)$ & $69(17.3)$ & 5.76 (4.11 to 8.08$)$ \\
\hline \multicolumn{5}{|c|}{ Family history of hypertension } \\
\hline No & $316(42.3)$ & 1.00 & $93(6.0)$ & 1.00 \\
\hline Yes & $103(39.8)$ & $0.89(0.67$ to 1.19$)$ & $31(5.3)$ & $0.87(0.58$ to 1.33$)$ \\
\hline Don't know & $195(48.4)$ & $-^{\star}$ & $29(4.5)$ & $-\star \star$ \\
\hline \multicolumn{5}{|c|}{ Family history of stroke } \\
\hline No & $35(44.3)$ & 1.00 & $16(10.5)$ & 1.00 \\
\hline Yes & $39(46.4)$ & $1.09(0.59$ to 2.02$)$ & $18(9.0)$ & $0.84(0.41$ to 1.70$)$ \\
\hline Don't know & $535(44.0)$ & $-\star \star$ & $116(4.9)$ & $-\star \star$ \\
\hline \multicolumn{5}{|c|}{ Body mass index } \\
\hline$<18.5$ & $48(42.1)$ & $0.68(0.43$ to 1.08$)$ & $17(3.61)$ & $0.40(0.22$ to 0.72$)$ \\
\hline $18.5-25$ & $48(42.1)$ & $0.68(0.43$ to 1.08$)$ & $17(3.61)$ & $0.40(0.22$ to 0.72$)$ \\
\hline$>25$ & $110(51.6)$ & 1.00 & $35(8.60)$ & 1.00 \\
\hline \multicolumn{5}{|l|}{ Hypertension } \\
\hline No & $520(42.9)$ & 1.00 & $110(4.7)$ & 1.00 \\
\hline Yes & $94(48.7)$ & $1.27(0.93$ to 1.72$)$ & $43(9.9)$ & $2.26(1.56$ to 3.27$)$ \\
\hline
\end{tabular}

${ }^{\star}{ }^{\star}$ A total of 2305 people (male 744, female 1561) did not know about a family history of hypertension and were treated as missing for this analysis.

Table 4 Multivariate logistical regression analysis for correlates of cigarette smoking

\begin{tabular}{|c|c|c|}
\hline Variable & Odds ratio $(95 \% C I)$ & $p$ Value \\
\hline \multicolumn{3}{|l|}{ Sex } \\
\hline Female & 1.00 & \\
\hline Male & $6.50(4.75$ to 8.79$)$ & 0.000 \\
\hline \multicolumn{3}{|l|}{ Education } \\
\hline None & 1.00 & \\
\hline Primary & $1.09(0.85$ to 1.41$)$ & 0.483 \\
\hline College & $0.55(0.35$ to 0.87$)$ & 0.011 \\
\hline Use of wine & $3.47(2.81$ to 4.29$)$ & 0.000 \\
\hline Use of snuff & $1.39(1.12$ to 1.73$)$ & 0.003 \\
\hline \multicolumn{3}{|l|}{ Occupation } \\
\hline Group 1 & $1.37(0.90$ to 2.09$)$ & 0.146 \\
\hline Group 2 & 1.55 (1.05 to 2.29$)$ & 0.027 \\
\hline Group 3 & $2.63(1.67$ to 4.14$)$ & 0.000 \\
\hline Group 4 & 1.00 & \\
\hline \multicolumn{3}{|l|}{ Body mass index } \\
\hline$<18.5$ & 0.55 (0.37 to 0.81$)$ & 0.002 \\
\hline $18.5-25$ & $0.74(0.57$ to 0.96$)$ & 0.023 \\
\hline$>25$ & 1.00 & \\
\hline Age (per 10 year increase) & $1.26(1.17$ to 1.35$)$ & 0.000 \\
\hline
\end{tabular}

Those who drank wine were 3.5 times as likely to be smokers (OR 3.5, $95 \%$ CI 2.81 to 4.29 ). Age, use of snuff, occupation as a farmer or a business, desirable and lower body mass index were also significantly associated with smoking in our final model.

We did not find any significant correlation between cigarette consumption and reported household income level. People working as businessmen and skilled workers were 2.6 times as likely to be smokers than government employees. Farmers were also more likely to be smokers (1.55 times). Studies are not available documenting use of cigarette in different occupations in Pakistan. Narayan and colleagues noted a low prevalence of smoking among professionals as compared to other professions in India. ${ }^{9}$
The proportion of men and women smoking cigarettes increased with the increase in age (1.26 times per 10 years). People with lower body mass index were more likely to smoke cigarettes.

\section{Discussion}

In this high mountain population of north Pakistan, a substantial number of people aged 18 years and over smoked cigarettes. The prevalence of smoking was much higher among men $(43.7 \%)$ than among women (5.5\%). Many men were away in our study sample which could be a source of under- or overestimation of the prevalence in the male population. We used the World Health Organization standard population for developing countries to obtain age adjusted prevalence. ${ }^{10}$ We found a lower prevalence $(40.5 \%$ ) among 
males but it remained more or less the same in females (6.3) after adjustment for age. Studies done in other rural populations of the country have reported a prevalence of $36.8 \%$ among men and 9.3\% among women. ${ }^{11}$ Anwar and colleagues reported a prevalence of $26 \%$ among people aged 15 years and over in a low socioeconomic urban population of Karachi, Pakistan. ${ }^{12}$ In urban India (Delhi) the prevalence of smoking was $45 \%$ among men and $7 \%$ among women. ${ }^{9}$

We did not ask about the brand of cigarettes consumed in our study. Asghar and colleagues reported that of the 47 brands of cigarettes in Pakistan, $87 \%$ had tar and $78.7 \%$ nicotine concentrations above the upper range of international levels $(20 \mathrm{mg} /$ cigarette for tar and $2 \mathrm{mg} /$ cigarette for nicotine). $^{2}$

In our study smoking initiation tended to occur at an early age, and the majority of the people started smoking before the age of 25 . In addition to cigarettes, tobacco was used as naswar (moist snuff), dried leaves of tobacco crushed and mixed with lime mixture and put inside the mouth as oral dip. Both men (39\%) and women $(14 \%)$ reported use of naswar. Moist snuff, a form of smokeless tobacco, contains nicotine, sodium, and liquorice, which are known to raise blood pressure. ${ }^{13-15}$ Other health hazards, such as oral cancer, are associated with snuff use..$^{16}$

In our study, use of wine was found to be an important correlate of smoking, and people who reported use of wine were 3.5 times as likely to be smokers than their non-used counterparts. Alcohol is a restricted substance in Pakistan, but people in this area used to crush grapes in local stone containers and used as wine. Studies have identified alcohol as a promoter for tobacco use, and tobacco smoking and alcohol drinking as the two most important risk factors for cancers of the upper aerodigestive tract. ${ }^{18} 19$

In our study the proportion of men and women smoking cigarettes increased with increasing age (1.26 times per 10 years). People with lower body mass index were more likely to smoke cigarettes. Other studies found a small increase in the prevalence of people becoming overweight after smoking cessation. ${ }^{21}$
The high prevalence of smoking, particularly in men, is a major problem. The results of this study should be useful in helping to plan more effectively tobacco control programmes in northern Pakistan.

This study was supported by the Seed grant number 02410 from the Dean's office of the Aga Khan University, Karachi. We also acknowledge the moral and material support extended by the Aga Khan Health Services Pakistan.

1 Ball K. Pakistan: attempts to control damage by tobacco smoking. Lancet 1983;ii: 1413.

2 Asghar M, Jan ZA. Monitoring of harmful constituents of cigarettes and tobacco in Pakistan. Fournal of the Pakistan Medical Association 1989;39:66-8.

3 Anon. Pakistan health education survey 1991-92. Islamabad: Ministry of Health, Government of Pakistan, 1993.

4 Pakistan Medical Research Council. National health survey of Pakistan. Network Publication Service, 1998.

5 Marsh MM, Kadir K, Husein, et al. Adult mortality in slums of Karachi, Pakistan. Fournal of the Pakistan Medical Association 2000;50:300-6.

6 Anon. Basic indicators for member states. The world health report, 1999. Geneva: WHO, 2000.

7 Fox Pro 2.6 (C) $1989+1994$ Microsoft Corporation (Engineering Prototype)

8 STATA Software version 6.0, College Station, Texas, USA

9 Narayan KMV, Chadha SL, Hanson RL, et al. Prevalence and patterns of smoking in Delhi: cross sectional study. BMf 1996;312:1576-9

10 World Health Organization. World standard population. World health statistics annual 1993. Geneva: World Health Organization, 1993.

11 Syed EA. Prevalence and pattern of smoking in Pakistan. Fournal of the Pakistan Medical Association 1998;48:64-6.

12 Anwar TM, Luby SP, Ghazala P. Smoking among males in a low socioeconomic area of Karachi. Fournal of the Pakistan Medical Association 1998;48:62-3.

13 Stamier R, Stamler J, Riedtinger WF, et al. Weight and blood pressure: findings in hypertension screening of 1 million Americans. $7 A M A$ 1978;240:1607-10.

14 Stewart P, Wallace A, Valentino R. Mineralocorticoid activity of liquorice: 11-beta hydroxysteroid dehydrogenese deficiency comes of age. Lancet 1987;ii:821-4

15 Moris D, Davis E, Latif S. Licorice, tobacco chewing and hypertension. N Engl f Med 1990;322:849.

16 Brennan JA, Boyle JO, Koch WM. Association between cigarette smoking and mutation of the p53 gene in squamous-cell carcinoma of the head and neck. N Engl $\mathcal{F}$ Med 1995;332:712-7.

17 Jayant K, Deo MG. Oral cancer and cultural practices in relation to betel quid and tobacco chewing and smoking. Cancer Detect Prev 1986;9:207-13.

18 Schlecht NF, Franco EL, Pinto J, et al. Interaction between tobacco and alcohol consumption and the risk of cancers of the upper aero-digestive tract in Brazil. Am f Epidemiol 1999;150:1129-37.

19 Blot WJ, McLaughlin JK, Winn DM, et al. Smoking and drinking in relation to oral and pharyngeal cancer. Cancer Res 1988;48:3282-7.

20 William DF, Madans J, Anda RF, et al. Smoking cessation and severity of weight gain in a national cohort. $N$ Engl $\mathcal{F}$ Med 1991;324:739-45.

21 Flegal KM, Troiano RP, Pamuk ER, et al. The influence of smoking cessation on the prevalence of overweight in the United States. N Engl 7 Med 1995;333:1165-70. 